\title{
Immunological Study of Pullulanase from Klebsiella Strains and the Occurrence of this Enzyme in the Enterobacteriaceae
}

\author{
YOSHIO KONISHI,' AKINORI AMEMURA,' SHIZUO TANABE, ${ }^{2}$ AND TOKUYA HARADA' \\ Institute of Scientific and Industrial Research' ${ }^{\prime}$ and Institute for Microbial Diseases, ${ }^{2}$ Osaka University, \\ Suita, Osaka (565) Japan
}

The abilities of various Enterobacteriaceae strains to grow on starch or pullulan and the occurrence of pullulanase in these strains were studied. Only the Klebsiella strains grew well on amylopectin and pullulan and produced pullulanase. None of the Enterobacter strains produced pullulanase. The pullulanase produced by various strains of Klebsiella was examined by the immunodiffusion method. Culture filtrates and cell extracts of all of the Klebsiella strains tested formed a precipitin line against antiserum prepared with crystalline pullulanase from $K$. pneumoniae IFO 3321. Except for K. pneumoniae IFO 3317 and ATCC 21073, these lines fused completely with the homologous line. No materials which crossreacted with the antiserum were produced by the other Enterobacteriaceae strains studied. The production of the enzyme is discussed as a character of potential use in the classification and identification of strains of Enterobacteriaceae.

Pullulanase (EC 3.2.1.41, pullulan 6-glucanohydrolase) is an enzyme that hydrolyzes the $(1 \rightarrow 6)-\alpha$-glucosidic linkages in pullulan to form maltotriose as the final product. Pullulanase was discovered by Bender and Wallenfels (3) in Aerobacter aerogenes, strains of which are now classified as members of either Enterobacter or Klebsiella. The enzyme has been reported to be formed in one or more strains of Escherichia intermedia (23), Streptococcus mitis (24), Bacillus cereus subsp. mycoides (22), and Lactobacillus plantarum (28). The pullulanase-producing strain of $E$. intermedia (ATCC 21073) has been reported by the American Type Culture Collection (ATCC) (2) to be an aberrant strain of Klebsiella pneumoniae.

Pullulanase, together with isoamylase, which was discovered by Harada et al. (10) in Pseudomonas amyloderamosa, has been used to elucidate the structures of polysaccharides and to produce useful materials, such as maltose and amylose, by debranching starch with and without $\beta$-amylase. We have compared the actions $(9,27)$ and molecular properties $(1,12)$ of the two enzymes previously.

Previously (26) we showed that Escherichia coli, Salmonella typhimurium, and Citrobacter freundii produce materials without enzyme activity that cross-react with anti- $K$. aerogenes arylsulfatase serum under conditions in which klebsiellae produce arylsulfatase. Thus, we became interested in the distribution of pullulanase and of the enzymically inactive protein in strains of the family Enterobacteriaceae. In this work, antiserum against $K$. pneumoniae pullu- lanase was prepared, and the distribution of pullulanase among some Enterobacteriaceae strains was studied enzymatically and immunologically.

\section{MATERIALS AND METHODS}

Bacterial strains. $E$. coli $\mathrm{K}-12(\lambda), S$. typhimurium LT2, and $K$. aerogenes W70 were obtained from $H$. Ogawa, Osaka University, T. Fukazawa, Keio University, and S. Yamagishi, Chiba University, respectively. $K$. pneumoniae ATCC 21073, previously identified as a strain of $E$. intermedia by Ueda and Nanri (23), who isolated the strain, was obtained from the ATCC. All other strains used were obtained from the Institute for Fermentation (IFO), Osaka.

Culture conditions. The medium used $(\mathrm{pH} \mathrm{7.2,}$ $100 \mathrm{ml})$ was composed of: $\left(\mathrm{NH}_{4}\right)_{2} \mathrm{HPO}_{4}, 0.15 \mathrm{~g}$; $\mathrm{KH}_{2} \mathrm{PO}_{4}, 0.1 \mathrm{~g} ; \mathrm{MgSO}_{4} \cdot 7 \mathrm{H}_{2} \mathrm{O}, 0.05 \mathrm{~g} ; \mathrm{NaCl}, 1 \mathrm{mg}$; $\mathrm{CaCl}_{2}, 1 \mathrm{mg} ; \mathrm{MnCl}_{2} \cdot 4 \mathrm{H}_{2} \mathrm{O}, 1 \mathrm{mg} ; \mathrm{FeCl}_{3} \cdot 6 \mathrm{H}_{2} \mathrm{O}, 1 \mathrm{mg}$; $\mathrm{CuSO}_{4} \cdot 5 \mathrm{H}_{2} \mathrm{O}, 5 \mu \mathrm{g} ; \mathrm{Na}_{2} \mathrm{MoO}_{4} \cdot 2 \mathrm{H}_{2} \mathrm{O}, 2 \mu \mathrm{g} ; \mathrm{ZnCl}_{2} \cdot 7 \mathrm{H}_{2} \mathrm{O}$, $1 \mu \mathrm{g} ; \mathrm{H}_{3} \mathrm{BO}_{3}, 1 \mu \mathrm{g}$; and a carbon source, $1 \mathrm{~g}$. Unless otherwise stated, organisms were grown aerobically at $30^{\circ} \mathrm{C}$ for 4 days in $500-\mathrm{ml}$ conical flasks by inoculating $5 \mathrm{ml}$ of seed culture in this medium into $95 \mathrm{ml}$ of fresh medium.

For the formation of pullulanase, organisms were grown in the same medium supplemented with $0.5 \%$ sodium glutamate, since this compound enhances formation of pullulanase. Cells were harvested by centrifugation at $10,000 \times g$ for $30 \mathrm{~min}$. The supernatant was assayed for pullulanase activity and immunological reactivity, whereas the precipitated cells were washed twice with saline and once with sodium phosphate buffer ( $\mathrm{pH} \mathrm{7.0)}$ and stored at $-20^{\circ} \mathrm{C}$ until used.

Preparation of cell extracts. Suspensions of cells in $0.02 \mathrm{M}$ sodium phosphate buffer ( $\mathrm{pH} 7.0$ ) were treated with $0.1 \%$ (final concentration) sodium dodecyl sulfate for $20 \mathrm{~h}$ at $30^{\circ} \mathrm{C}$ by the method of Ohba and 
Ueda (15). The mixtures were centrifuged, and the resultant supernatants were dialyzed against the buffer described above and used for enzymatic and immunological assays. Cell extracts obtained by sonic oscillation for $20 \mathrm{~min}$ at $20 \mathrm{kcycles}$ and at $<6^{\circ} \mathrm{C}$ were used as controls.

Enzyme assay. Pullulanase activity was measured in $2 \mathrm{ml}$ of reaction mixture consisting of $1 \mathrm{ml}$ of $1 \%$ pullulan solution in $0.1 \mathrm{M}$ acetate buffer ( $\mathrm{pH} \mathrm{5.5)}$ and the enzyme solution. The reaction was carried out for $15 \mathrm{~min}$ at $40^{\circ} \mathrm{C}$, and the release of aldehyde groups was then determined by the Nelson method (13). One unit of activity was defined as the amount of enzyme causing liberation of $1 \mu \mathrm{mol}$ of aldehyde group per min.

Preparation of antiserum. Three 6-month-old male New Zealand white rabbits were injected intramuscularly with $2 \mathrm{ml}$ of an emulsion consisting of $1 \mathrm{ml}$ of Freund incomplete adjuvant, $1 \mathrm{ml}$ of $0.85 \% \mathrm{NaCl}$ in

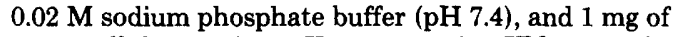
pure pullulanase from $K$. pneumoniae IFO 3321. As booster injections, they were given the same type of injection 2 weeks later and then subcutaneous injections of $1 \mathrm{mg}$ of the enzyme in incomplete adjuvant at 2-week intervals. Blood was collected from an ear vein 7 days after each booster injection. Control sera were obtained from rabbits before immunization.

Immunodiffusion. Experiments were carried out by the Stollar and Levine modification (21) of the Ouchterlony technique. Glass plates $(2.6$ by $7.6 \mathrm{~cm})$ were coated with $1.1 \%$ agar in sodium phosphate buffer-saline ( $\mathrm{pH} 7.4)$ to a thickness of $0.1 \mathrm{~cm}$. Two microliters of undiluted antiserum followed by $2-\mu \mathrm{l}$ volumes of concentrated culture supernatant and cell extracts or appropriately diluted samples of pullulanase were put into the sample wells. Sufficient material was added to sample wells to give 50 to $100 \mathrm{mU}$ of pullulanase activity if enzyme activity was present, or three times as much protein as that of the preparation from $K$. pneumoniae IFO 3321 if activity was not present. Samples were concentrated by precipitation with ammonium sulfate. Plates were incubated overnight in a high-humidity chamber at $30^{\circ} \mathrm{C}$ and then examined for precipitin lines. The plates were washed eight times with $0.85 \% \mathrm{NaCl}$ to remove non-precipitated protein and were then stained with $0.5 \%$ amido black.

Immunoelectrophoresis. The homogeneity of pullulanase antiserum was tested immunoelectrophoretically by a minor modification of the Scheidegger method (19). Wells $2 \mathrm{~mm}$ in diameter were punched in a coating of $1 \%$ agarose (in barbital-acetate buffer, $\mathrm{pH}$ 8.6 ) on a glass slide ( 5 by $8 \mathrm{~cm}$ ). Approximately $2 \mu \mathrm{l}$ of crude or purified enzyme solution was placed in each well. After electrophoresis was carried out at 5 to 7 $\mathrm{V} / \mathrm{cm}$ for $60 \mathrm{~min}$ with the same buffer, $140 \mu \mathrm{l}$ of pullulanase antiserum was put into the trough, and the slide was placed overnight in a high-humidity chamber at $30^{\circ} \mathrm{C}$. The slide was then washed with $0.85 \% \mathrm{NaCl}$ to remove excess protein and was stained with $0.5 \%$ amido black.

Chemicals. Crystalline pullulanase and pullulan were kindly supplied by Hayashibara Biochemical Laboratory, Okayama, Japan. Waxy corn amylopectin was obtained from Nichiden Kagaku Industries, Osaka, Japan. Soluble starch was purchased from
Wako Pure Chemicals, Osaka, Japan. Other chemicals were commercial products of the highest purity available.

\section{RESULTS}

Specificity of antipullulanase. When homologous crystalline pullulanase from $K$. pneumoniae IFO 3321 and the supernatant of a culture of the same strain grown with soluble starch were tested by the immunodiffusion method, both preparations gave a single sharp precipitin line, and these lines fused completely, indicating that the two antigens were identical and also that the antiserum was immunologically pure (Fig. 1). These findings were confirmed by immunoelectrophoresis of crystalline and crude preparations of the enzyme (Fig. 2). The slight difference in mobility of the two samples was probably due to the effect of impurities in the crude preparation. Serum from nonimmunized animals did not show any reaction with the pullulanase preparations.

Pullulanase was shown by Wallenfels et al. (25) and Fujio et al. (8) to be formed either extracellularly or in a cell-bound state, depending upon the culture conditions. The lines

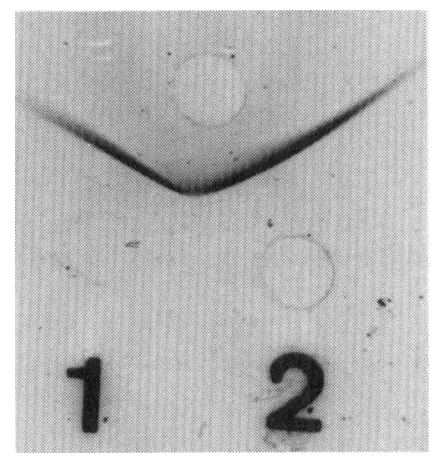

Fig. 1. Immunodiffusion of pullulanase from $K$. pneumoniae IFO 3321 with antiserum. Purified and crude enzyme preparations $(2 \mu l ; 50 \mathrm{mU})$ were placed in wells 1 and 2, respectively, and antiserum $(2 \mu l)$ was placed in the upper well.

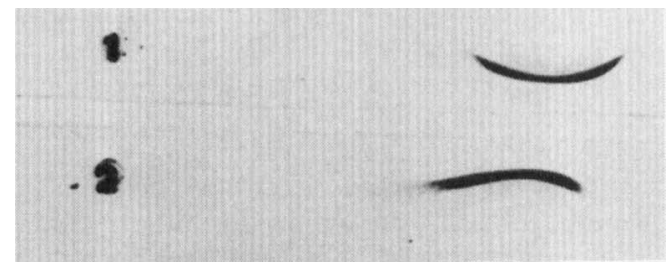

Fig. 2. Immunoelectrophoresis of pullulanase from $K$. pneumoniae IFO 3321 with antiserum. Purified and crude enzyme preparations $(2 \mu \mathrm{l} ; 140 \mathrm{mU})$ were placed in wells 1 and 2, respectively, and antiserum $(140 \mu l)$ was placed in the center trough. 
formed by the preparations of extracellular and intracellular enzymes fused completely with each other. Thus, both enzymes were found to be the same immunologically.

Growth of various strains of Enterobacteriaceae on amylopectin, soluble starch, or pullulan, and pullulanase formation by the strains. The occurrence of pullulanase in strains of Enterobacteriaceae was examined. A debranching enzyme such as pullulanase is a com- ponent of the starch- or pullulan-utilizing system in several bacteria. We first investigated utilization, by the strains, of amylopectin, soluble starch, and pullulan as sole carbon sources.

All eight strains of Klebsiella grew well on waxy corn amylopectin, soluble starch, and pullulan (Table 1). None of the other strains tested grew appreciably on waxy corn amylopectin, but E. coli K-12( $\lambda)$, $S$. typhimurium LT2, all strains of Enterobacter tested, and Serratia marces-

TABLE 1. Growth of various strains of Enterobacteriaceae on waxy corn amylopectin, soluble starch, and pullulan, and pullulanase activity in the supernatants of maltose-grown cultures

\begin{tabular}{|c|c|c|c|c|c|c|}
\hline \multirow{2}{*}{ Strain $^{\alpha}$} & \multicolumn{3}{|c|}{ Growth $\left(A_{600}\right)^{b}$} & \multicolumn{3}{|c|}{$\begin{array}{l}\begin{array}{l}\text { Pullulanase formation in maltose } \\
\text { medium }\end{array}\end{array}$} \\
\hline & $\begin{array}{l}\text { Waxy corn } \\
\text { amylopectin }\end{array}$ & $\begin{array}{l}\text { Soluble } \\
\text { starch }\end{array}$ & Pullulan & $\begin{array}{l}\text { Growth } \\
\left(A_{600}\right)^{b}\end{array}$ & Activity & $(\mathrm{U} / \mathrm{ml})$ \\
\hline Escherichia coli $\mathrm{K}-12(\lambda)$ & 0.0 & 1.1 & 0.0 & 4.8 & $<0.001$ & $(<0.01)$ \\
\hline E. coli B . . . . . . . & 0.0 & 0.0 & 0.0 & 5.1 & $<0.001$ & \\
\hline Citrobacter freundii IFO $12681 \ldots \ldots$ & 0.0 & 0.0 & 0.0 & 6.3 & $<0.001$ & \\
\hline Salmonella typhimurium LT2 & 0.0 & 0.8 & 0.0 & 4.4 & $<0.001$ & $(<0.01)$ \\
\hline Klebsiella aerogenes W70 & 1.1 & 2.8 & 3.0 & 6.3 & 0.18 & $(1.5)$ \\
\hline K. pneumoniae IFO 3317 & 1.6 & 2.6 & 2.6 & 6.0 & 0.004 & $(0.05)$ \\
\hline K. pneumoniae IFO 3318 & 1.5 & 2.6 & 2.5 & 6.2 & 0.15 & (1.1) \\
\hline K. pneumoniae IFO 3319 & 1.5 & 2.5 & 2.7 & 4.4 & 0.22 & (1.7) \\
\hline K. pneumoniae IFO 3321 & 1.2 & 1.6 & 2.2 & 3.9 & 0.20 & (1.6) \\
\hline K. pneumoniae IFO 12059 & 1.4 & 2.6 & 1.8 & 7.9 & 0.01 & $(0.10)$ \\
\hline$K$ pneumoniae IFO $13541 \ldots \ldots \ldots$ & 1.1 & 2.5 & 2.0 & 5.9 & 0.05 & $(0.24)$ \\
\hline K. pneumoniae ATCC 21073 (Esche- & & & & & & \\
\hline richia intermedia) & 1.4 & 2.8 & 0.8 & 6.0 & 0.04 & $(0.32)$ \\
\hline Enterobacter cloacae IFO $3320 \ldots \ldots$ & 0.0 & 0.6 & 0.0 & 3.0 & $<0.001$ & $(<0.01)$ \\
\hline E. cloacae IFO $12935 \ldots \ldots \ldots \ldots$ & 0.0 & 1.1 & 0.0 & 6.7 & $<0.001$ & $(<0.01)$ \\
\hline E. cloacae IFO 12937 & 0.0 & 1.7 & 0.0 & 7.4 & $<0.001$ & $(<0.01)$ \\
\hline E. cloacae IFO 13535 & 0.0 & 1.7 & 0.0 & 6.4 & $<0.001$ & $(<0.01)$ \\
\hline E. cloacae IFO 13536 & 0.0 & 0.5 & 0.0 & 5.6 & $<0.001$ & $(<0.01)$ \\
\hline E. aerogenes IFO 12010 & 0.0 & 0.7 & 0.2 & 6.2 & $<0.001$ & $(<0.01)$ \\
\hline E. aerogenes IFO 13534 & 0.0 & 0.6 & 0.2 & 6.7 & $<0.001$ & $(<0.01)$ \\
\hline E. liquefaciens IFO 12979 & 0.0 & 1.6 & 0.0 & 8.0 & $<0.001$ & $(<0.01)$ \\
\hline E. liquefaciens IFO 13537 & 0.0 & 0.9 & 0.1 & 5.0 & $<0.001$ & $(<0.01)$ \\
\hline Serratia marcescens IFO 3046 & 0.0 & 0.0 & 0.2 & 1.8 & $<0.001$ & \\
\hline S. marcescens IFO $3735 \ldots$ & 0.0 & 1.1 & 0.2 & 4.4 & $<0.001$ & $(<0.01)$ \\
\hline S. marcescens IFO 12648 & 0.0 & 1.2 & 0.2 & 3.9 & $<0.001$ & $(<0.01)$ \\
\hline S. marcescens IFO 12946 & 0.0 & 0.5 & 0.2 & 3.9 & $<0.001$ & $(<0.01)$ \\
\hline Proteus inconstans IFO 12930 & 0.0 & 0.0 & 0.0 & $3.0^{d}$ & $<0.001^{d}$ & \\
\hline P. morganii IFO $3168 \ldots \ldots$ & $0.0^{e}$ & $0.0^{e}$ & $0.1^{e}$ & $0.7^{d}$ & $<0.001^{d}$ & \\
\hline P. mirabilis IFO 3849 & $0.1^{e}$ & $0.0^{e}$ & $0.0^{e}$ & $3.3^{d}$ & $<0.001^{d}$ & \\
\hline P. vulgaris IFO 3045 & $0.1^{e}$ & $0.2^{e}$ & $0.2^{e}$ & $4.5^{d}$ & $<0.001^{d}$ & \\
\hline P. vulgaris IFO 3167 & $0.1^{e}$ & $0.2^{e}$ & $0.3^{e}$ & $8.1^{d}$ & $<0.001^{d}$ & \\
\hline P. vulgaris IFO 3851 & $0.0^{e}$ & $0.1^{e}$ & $0.2^{e}$ & $6.8^{d}$ & $<0.001^{d}$ & \\
\hline P. vulgaris IFO 3988 & $0.1^{e}$ & $0.1^{e}$ & $0.2^{e}$ & $2.3^{d}$ & $<0.001^{d}$ & \\
\hline P. rettgeri IFO 13501 & 0.0 & 0.0 & 0.0 & $2.5^{d}$ & $<0.001^{d}$ & \\
\hline Erwinia amylovora IFO $12687 \ldots$ & $0.0^{e}$ & $0.0^{e}$ & $0.1^{e}$ & $1.8^{d}$ & $<0.001^{d}$ & \\
\hline E. carotovora IFO $3380 \ldots \ldots$ & 0.0 & 0.0 & 0.2 & $1.2^{d}$ & $<0.001^{d}$ & \\
\hline
\end{tabular}

${ }^{a}$ The organisms were grown aerobically for 4 days at $30^{\circ} \mathrm{C}$ (or $27^{\circ} \mathrm{C}$ for E. amylovora IFO 12687) in the synthetic medium as described in the text but containing $1 \%$ of the sugar indicated.

${ }^{b}$ Numbers indicate increases in absorbance at $600 \mathrm{~nm}$.

${ }^{c}$ Numbers in parentheses represent pullulanase activities in soluble starch medium.

${ }^{d}$ Yeast extract $(0.1 \%$ final concentration) was added to the synthetic medium because these strains were unable to grow well in the medium.

${ }^{e}$ Yeast extract and peptone $(0.1 \%$ each final concentration) were added to the synthetic medium because these strains were unable to grow in the medium. The numbers indicate values with sugar minus those without sugars. 
cens IFO 3735, IFO 12648, and IFO 12946 grew fairly well on soluble starch. All of the Enterobacter aerogenes and $S$. marcescens strains tested, some Proteus strains, and Erwinia carotovora IFO 3380 grew slightly on pullulan; these strains seemed to produce trace amounts of pullulanase or of some other pullulan-degrading enzymes. $E$. coli K-12( $(\lambda), S$. typhimurium LT2, all strains of Enterobacter cloacae tested, and Enterobacter liquefaciens IFO 12979, which can grow on starch but not on pullulan, seemed to produce another amylase.

Pullulanase activity (Table 1) was assayed in the supernatants of cultures grown in maltose medium, which induces pullulanase in $K$. pneumoniae (7); the soluble-starch medium was also used for assays of strains which grew in this medium. Under the culture conditions used, pullulanase was formed mainly in the supernatant. All eight strains of Klebsiella studied produced pullulanase; none of the other strains tested produced any detectable pullulanase in either medium, even when the supernatant was concentrated 20 times by salting-out and incubated with substrate for $24 \mathrm{~h}$. Moreover, none of the cell extracts obtained by sonic oscillation or sodium dodecyl sulfate extraction except those of Klebsiella strains showed any activity. The culture supernatants of $E$. coli $\mathrm{K}-12(\lambda)$, Enterobacter cloacae IFO 12937, IFO 13535, and IFO 13536, Enterobacter aerogenes IFO 12010 and IFO 13534, Enterobacter liquefaciens IFO 12979, and S. marcescens IFO 3735 and IFO 12648 contained activity for decomposition of soluble starch, which activity was detected by measuring the increase of reducing sugar.

Pullulanase has been known to be produced by many strains of Aerobacter aerogenes $(3,5$, $7,9)$, which are now classified as members of Enterobacter or of Klebsiella. However, no pullulanase has been detected among strains of Enterobacter.

Immunodiffusion of pullulanase from Klebsiella. The eight strains of Klebsiella, which produce pullulanase, were cultured in soluble-starch medium, and the supernatants were tested for reactivity against antiserum from $K$. pneumoniae IFO 3321 pullulanase. The culture supernatants from all of the strains cross-reacted with the antiserum (Fig. 3A and B). The precipitin lines of the preparations from $K$. aerogenes W70 and $K$. pneumoniae IFO 3318, IFO 3319 , IFO 3321, IFO 12059, and IFO 13541 fused completely with each other (Fig. 3A). Those of the preparations from $K$. pneumoniae IFO 3317 and $K$. pneumoniae ATCC 21073 also fused completely with each other; however, they formed a spur with the homologous line (Fig. 3B), an indication that these pullulanases do not possess
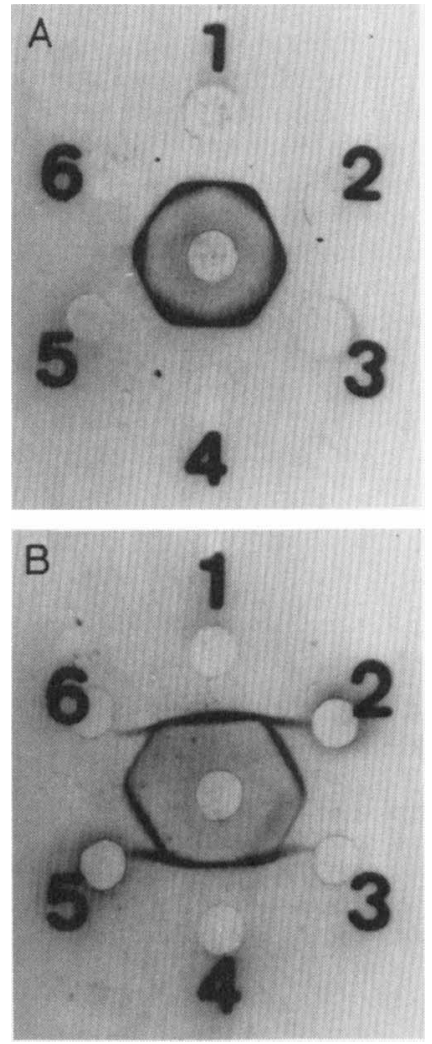

FIG. 3. Immunodiffusion experiment demonstrating cross-reactions between pullulanases of Klebsiella and antiserum to pullulanase from $K$. pneumoniae IFO 3321. The center wells contained $2 \mu \mathrm{l}$ of antiserum. (A) Sample wells contained concentrated culture supernatants ( $2 \mu \mathrm{l} ; 50$ to $100 \mathrm{mU}$ ) from the following strains: (1) IFO 3321; (2) W70; (3) IFO 3318; (4) IFO 3319; (5) IFO 12935; and (6) IFO 13541. (B) Sample wells contained concentrated culture supernatants $(2 \mu \mathrm{l} ; 50$ to $100 \mathrm{mU})$ from the following strains: (1,4) IFO 3321; (2,5) IFO 3317; and $(3,6)$ ATCC 21073.

all of the antigenic determinants found in the pullulanase of the other strains. The extracts of the cells obtained by treatment with sodium dodecyl sulfate gave similar reactions.

To determine whether any proteins without pullulanase activity but with cross-reactivity against antipullulanase were produced, concentrates of culture supernatants and cell extracts from other strains of Enterobacteriaceae were tested by the diffusion method. However, no such proteins were detected in the preparations.

\section{DISCUSSION}

Enevoldsen et al. (6) reported a new method, using antibodies towards crude pullulanase for cross-immunoelectrophoresis, to follow the pu- 
rification of this enzyme, but they did not report the immunological properties of the antibody towards pullulanase. Our immunological analysis showed that the pullulanases of Klebsiella can be divided into two groups: the first contains the pullulanases of $K$. aerogenes $\mathrm{W} 70$ and $K$. pneumoniae IFO 3318 , IFO 3319 , IFO 3321, IFO 12059 , and IFO 13541, and the other contains the pullulanases of $K$. pneumoniae IFO 3317 and ATCC 21073. The former are homologous, but the latter are heterologous, because their precipitin lines form a spur with the homologous line. Previously we found that the precipitin line of strain 3317 with arylsulfatase fused partially with the homologous line to the antiserum prepared against pure arylsulfatase of $K$. aerogenes W70, whereas the lines of other arylsulfatasepositive strains of $K$. pneumoniae fused completely (26). These immunological results with the two enzymes suggest that strain 3317 differs significantly from other strains of $K$. pneumoniae. Another strain, ATCC 21073, which produces heterologous pullulanase, was originally isolated by Ueda and Nanri (23) and identified as Escherichia intermedia. Strains of $E$. intermedia are now classified as members of Citrobacter intermedius (20); however, the abovementioned isolate is classified as an aberrant strain of $K$. pneumoniae (2). This strain differs from other $K$. pneumoniae strains with respect to the Voges-Proskauer and methyl red reactions, and, as reported here, its pullulanase is immunologically different from those of other $K$. pneumoniae strains. Hori and Osawa (11) conducted a taxonomic study involving ribosomal protein composition and reported that strains IFO 3317 and ATCC 21073 differ from other Klebsiella strains and belong to one and the same group.

Among the strains of Enterobacteriaceae tested, $E$. coli $\mathrm{K}-12(\lambda)$, all strains of Enterobacter, and S. marcescens IFO 3735, IFO 12648, and IFO 12946 grew well on soluble starch but did not produce pullulanase. Only strains of Klebsiella produced pullulanase activity and material with immunological reactivity against antipullulanase. In Bergey's Manual of Determinative Bacteriology, 8th ed. $(16,18)$, all motile Aerobacter strains were placed in Enterobacter, and the nonmotile strains were placed in Klebsiella. This classification is consistent with that based on pullulanase formation. Thus, pullulanase formation may be a character common to all klebsiellae and, if so, it may be a key character in differentiating strains of Klebsiella from other strains of Enterobacteriaceae. Obviously, to determine this, large numbers of strains will have to be studied.

Palmer et al. (17) reported the occurrence of a pullulanase in $E$. coli $\mathrm{ML}$, but Dessein and Schwartz (3) were dubious about this finding, since on careful examination they themselves detected no pullulanase in 11 strains of $E$. coli, including strain ML. We could not detect pullulanase enzymatically or immunologically in strains $\mathrm{K}-12(\lambda)$ and B of $E$. coli.

\section{ACKNOWLEDGMENT}

We thank I. Banno of the Institute for Fermentation, Osaka, for his valuable advice and hospitality.

\section{REPRINT REQUESTS}

Address reprint requests to: Professor Tokuya Harada, Institute of Scientific and Industrial Research, Osaka University, Suita, Osaka (565), Japan.

\section{LTTERATURE CITED}

1. Amemura, A., H. Kitagawa, and T. Harada. 1975. Role of the tryptophan group in the action of pullulanase of Aerobacter aerogenes. J. Biochem. 77:575-578.

2. American Type Culture Collection. 1978. American Type Culture Collection: catalogue of strains I, 13th ed., p. 79. American Type Culture Collection, Rockville, Md.

3. Bender, H., and K. Wallenfels. 1961. Untersuchungen an Pullulan. II. Spezifischer Abbau durch ein bacterielles Enzym. Biochem. Z. 334:79-95.

4. Dessein, A., and M. Schwartz. 1974. Is there pullulanase in Escherichiae coli? Eur. J. Biochem. 45:363-366.

5. Eisele, B., I. R. Rasched, and K. Wallenfels. 1972. Molecular characterization of pullulanase from Aerobacter aerogenes. Eur. J. Biochem. 26:62-67.

6. Enevoldsen, B. S., L. Reimann, and N. L. Hansen. 1977. Biospecific affinity chromatography of pullulanase. FEBS Lett. 79:121-124.

7. Fujio, Y., M. Sambuichi, and S. Ueda. 1970. Isoamylase production by Aerobacter aerogenes. (II) Some quantitative results by batch culture. J. Ferment. Technol. 48:601-606.

8. Fujio, Y., M. Shiosaka, and S. Ueda. 1970. Isoamylase production by Aerobacter aerogenes. (I) Effect of nitrogen source. J. Ferment. Technol. 48:8-13.

9. Harada, T., A. Misaki, H. Akai, K. Yokobayashi, and K. Sugimoto. 1972. Characterization of Pseudomonas isoamylase by actions on amylopectin and glycogen; comparison with Aerobacter pullulanase. Biochim. Biophys. Acta 268:497-505.

10. Harada, T., K. Yokobayashi, and A. Misaki. 1968. Formation of isoamylase by Pseudomonas. Appl. Microbiol. 16:1439-1444.

11. Hori, H., and S. Osawa. 1978. Evolution of ribosomal proteins in Enterobacteriaceae. J. Bacteriol. 133: 1089-1095.

12. Kitagawa, H., A. Amemura, and T. Harada. 1975. Studies on the inhibition and molecular properties of crystalline Pseudomonas isoamylase. Agric. Biol. Chem. 39:989-994.

13. Nelson, N. 1944. A photometric adaption of the Somogyi method for the determination of glucose. J. Biol. Chem. 153:375-380.

14. Lowry, O. H., N. J. Rosebrough, A. L. Farr, and R. J. Randall. 1951. Protein measurement with the Folin phenol reagent. J. Biol. Chem. 193:265-275.

15. Ohba, R., and S. Ueda. 1973. Purification, crystallization and some properties of intracellular pullulanase from Aerobacter aerogenes. Agric. Biol. Chem. 37:28212826.

16. Orskov, I. 1974. Genus VI. Klebsiella revisan 1885, 105 
nom. cons. Opin. 13, Jud. Comm. 1954, p. 321-324. In R. E. Buchanan and N. E. Gibbons (ed.), Bergey's manual of determinative bacteriology, 8 th ed. The Williams \& Wilkins Co., Baltimore.

17. Palmer, T. N., G. Wöber, and W. J. Whelan. 1973. The pathway of exogenous and endogenous carbohydrate utilization in Escherichia coli: a dual function for the enzymes of the maltose operon. Eur. J. Biochem. 39: 601-612.

18. Sakazaki, R. 1974. Genus VII. Enterobacter Hormaeche and Edwards 1960, 72 nom. cons. Opin. 28, Jud. Comm. 1963 , p. 324-325. In R. E. Buchnan and N. E. Gibbons (ed.), Bergey's manual of determinative bacteriology, 8 th ed. The Williams \& Wilkins Co., Baltimore.

19. Scheidegger, J. J. 1955. Une micro-méthode de l'immunoélectrophorése. Int. Arch. Allergy. 7:103-110.

20. Sedlák, J. 1974. Genus III. Citrobacter Werkman and Gillen 1932, p. 296-298. In R. E. Buchnan and N. E. Gibbons (ed.), Bergey's manual of determinative bacteriology, 8th ed. The Williams \& Wilkins Co., Baltimore.

21. Stollar, K., and L. Levine. 1963. Two-dimensional diffusion. Methods Enzymol. 6:838-854.

22. Takasaki, Y. 1976. Production and utilization of $\beta$-amylase and pullulanase from Bacillus cereus var. my. coides. Agric. Biol. Chem. 40:1515-1522.

23. Ueda, S., and N. Nanri. 1967. Production of isoamylase by Escherichia intermedia. Appl. Microbiol. 15: 492-496.

24. Walker, G. J. 1968. Metabolism of the reserve polysaccharide of Streptococcus mitis. Some properties of a pullulanase. Biochem. J. 108:33-40.

25. Wallenfels, K., H. Bender, and J. R. Rached. 1966. Pullulanase from Aerobacter aerogenes; production in a cell-bound state. Purification and properties of the enzyme. Biochem. Biophys. Res. Commun. 22:254-266.

26. Yamada, T., Y. Murooka, and T. Harada. 1978. Comparative immunological study of arylsulfatase in bacteria of the family Enterobacteriaceae: occurrence of latent arylsulfatase protein, regulated by sulfur compounds and tyramine. J. Bacteriol. 133:536-541.

27. Yokobayashi, K., H. Akai, T. Sugimoto, M. Hirao, K. Sugimoto, and T. Harada. 1973. Comparison of the kinetic parameters of Pseudomonas isoamylase and Aerobacter pullulanase. Biochim. Biophys. Acta. 293: 197-202.

28, Yoshida, M., K. Masuda, S. Sakai, M. Kurimoto, K. Yokobayashi, and M. Hirao. 1971. Degradation of starch by isoamylase and pullulanase. Tech. Res. Rep. Starch 69:21-28. (In Japanese.) 